\title{
An epidemiological study of facial clefting in Manitoba
}

\author{
JOAN WELCH AND ALASDAIR G W HUNTER \\ From the Department of Paediatrics, Children's Hospital of Winnipeg, and University of Manitoba, \\ Winnipeg, Manitoba, Canada
}

SUMMARY The results of an epidemiological survey of facial clefting in the province of Manitoba which covered the years 1964 to 1977 , inclusive, are reported. The mean annual incidence of total facial clefts was 2 in 1000 births; the incidence of cleft lip \pm cleft palate (CLP), and of cleft palate (CP), unassociated with a syndrome or two or more major malformations, was 1.05 in 1000 and 0.46 in 1000 , respectively. Mennonite infants were over-represented in the CLP group and Amerindian infants in both the CLP and CP groups. These ethnic groups also had more familial cases and showed higher average coefficients of inbreeding. Recurrence rates among sibs were found to be influenced by the presence or absence of additional affected relatives and by the presence of malformations in the proband. It is possible that these latter two variables may not be independent.

This study was undertaken in order to assess the incidence of facial clefting in Manitoba, to search for possible associations of clefting with demographic variables, and to determine the recurrence rates of facial clefting in families ascertained through an affected child. Of particular interest was how the occurrence of affected second and third degree relatives of the proband, and the presence or absence of additional malformations, would influence recurrence rates.

\section{Methods}

Children born with facial clefts in the province of Manitoba from 1 January 1964 to 31 December 1977, inclusive, were ascertained through a direct search of the records of all Winnipeg hospitals, the Provincial Congenital Anomalies Registry, dental records of the Orthodontic Department of the University of Manitoba and of private Manitoba orthodontists, and through inquiries to other provincial hospitals and nursing stations.

Surgical repair of facial clefts in Manitoba has been limited to Winnipeg hospitals throughout the study period and there are no neighbouring extraprovincial centres that draw patients away from the province for surgery. Treatment of facial clefts is the rule in surviving infants and ascertainment of this group is likely to be close to $100 \%$. Some infants who were stillborn or died in the perinatal period may have been missed.

Received for publication 6 June 1979
An attempt was made to contact the families of affected children in order to complete a questionnaire and to supplement information contained in the various medical records. Approximately half the families were contacted; appropriate adjustments were made for missing data. The data were coded for analysis by computer.

Each case was assigned first to either the cleft palate without cleft lip (CP), or to the lateral cleft lip with or without cleft palate (CLP) group. ${ }^{1}$ Patients with a recognised syndrome or multiple congenital anomalies (MCA) (defined here as two or more major malformations in addition to the cleft) were considered separately. In addition, for some aspects of the study, the CP and CLP patients were further subdivided according to the type of additional malformations present: none, one minor, more than one minor, one major, one major plus minor.

\section{Results and discussion}

A total of 507 children with facial clefts from 492 Manitoba families was ascertained. In the event that more than one affected child was born into a family during the study period, the oldest child was normally considered the index case or proband. The proband of these multiply ascertained families is marked with an asterisk in the appendix.* All 507 cases were used in such calculations as incidence and

*The details of each case are shown in an appendix, available from the authors on request. 
sex ratios, whereas each family was counted only once when considering associated variables that would have been biased by repeated inclusion of the same data.

There was no evidence of any secular change in incidence over the study period and the average annual incidence of 2.00 per 1000 births is in the middle range of values reported from previous studies. $^{2}{ }^{3}$ In 108 cases $(21 \cdot 3 \%)$ from 105 families the cleft was part of a recognised syndrome or malformation complex. The remaining 399 cases consisted of 264 cases of CLP from 258 families, 124 cases of CP from 121 families, and 11 cases lacking information as to cleft type or the presence or absence of associated malformations or both. The mean annual incidence of CLP was 1.04 in 1000 births and of $\mathrm{CP}$ was 0.46 in 1000 births; these figures are comparable to previous reports. ${ }^{12}$

In table 1 the CLP and CP patients are subdivided according to sex, and the location and severity of defect. A significant male excess in CLP was confirmed $(p<0 \cdot 005),{ }^{1-6}$ and more severe defects $(\mathrm{CL}+\mathbf{P}$ and clefts of both the hard and soft palate) were more frequent than either isolated $\mathrm{CL}$ or cleft

TABLE 1 Sex ratio, location, and severity of facial clefting

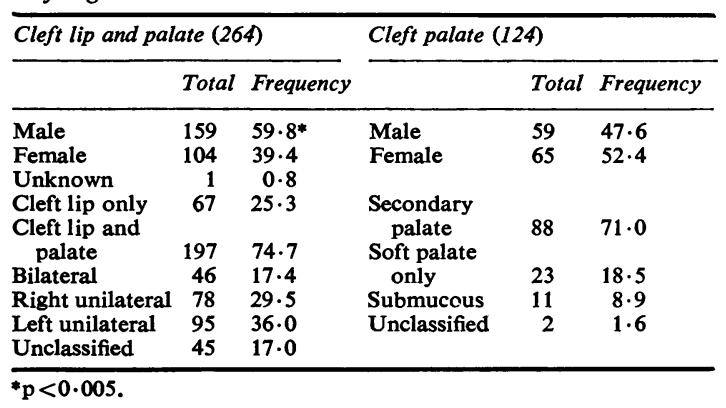

of the soft palate. Previous studies have found an $\frac{\mathbb{D}}{\overparen{D}}$ excess of left over right unilateral CLP cases $^{15-7} ; \stackrel{\mathbb{P}}{?}$ although we observed this trend the difference was not significant.

There was an excess of female cases of CP but this did not reach the level of significance noted in $\overline{\mathrm{c}}$ previous studies. ${ }^{6} 8$ Emmanuel $^{8}$ found that the $\underset{\nabla}{\overparen{D}}$ deviation from $1: 1$ in the sex ratio usually observed $\triangle$ for CLP and CP patients was not seen in patients $\tilde{\complement}$ with associated major malformations. The male $\vec{\circ}$ excess in CLP was maintained for all subgroups in $\overrightarrow{-}$ our sample except those with MCAs and syndromes; $\vec{\omega}$ the sex ratio did not differ from 1:1 in any of the $\mathrm{CP}$ subgroups.

Even after cases with recognised syndromes or $\overrightarrow{\vec{H}}$ multiple anomalies had been removed, $15.4 \%$ of i CLP and $16.0 \%$ of CP patients had at least one $\vec{N}$ major or minor anomaly or both. Seven of $252 \mathrm{~V}$ $(2.78 \%)$ CLP cases and four of $118(3.39 \%) \mathrm{CP}$ 은 cases had congenital heart defects (mostly ventricular septal defects). This incidence is significantly greater $\rightarrow$ than that in the general population ${ }^{9}$ for the CLP cases $(p<0.025)$, but does not attain significance for $\vec{\bullet}$ the CP patients where the numbers are smaller.

Mean paternal age was 29.7 years for the CLP group, 30.0 years for the $\mathrm{CP}$ group, and 26.5 years for the general population. ${ }^{10}$ Mean maternal age was 26.2 years for both the CLP and CP groups, compared to a population mean of 23.1 years. ${ }^{10}$ Mean parity was 2.8 for the CLP and 2.7 for the CP mothers, compared to 2.4 among the general population. Parental age and parity appear to be increased, but the nature of the control data did not allow formal significance testing. Several previous studies have suggested a possible parental age effect. ${ }^{11}$

Racial and ethnic variation in the incidence of $\frac{5}{3}$ facial clefting is well established. ${ }^{18}$ The population

TABLE 2 Distribution of cases by ethnic group

\begin{tabular}{|c|c|c|c|c|c|}
\hline \multirow[t]{2}{*}{ Ethnic group } & \multirow{2}{*}{$\begin{array}{l}\text { Proportion of } \\
\text { population. } \\
\text { Mean of male and } \\
\text { female }\end{array}$} & \multirow{2}{*}{\multicolumn{2}{|c|}{$\frac{C L(P)}{\text { No of cases }}$}} & \multicolumn{2}{|l|}{$C P$} \\
\hline & & & & No of case & \\
\hline $\begin{array}{l}\text { British Isles } \\
\text { French }\end{array}$ & $\begin{array}{l}0.415 \\
0.09\end{array}$ & $\begin{array}{l}85 \\
16\end{array}$ & $\begin{array}{l}89 \cdot 5 \\
19 \cdot 5\end{array}$ & $\begin{array}{r}38 \\
4\end{array}$ & $\begin{array}{l}39 \\
8 \cdot 5\end{array}$ \\
\hline $\begin{array}{c}\text { German/Dutch } \\
\text { (Mennonite) }\end{array}$ & $0 \cdot 16$ & 47 & $34 \cdot 5^{*}$ & 13 & 15 \\
\hline $\begin{array}{l}\text { Italian } \\
\text { Slavic, Slovak }\end{array}$ & $\begin{array}{l}0.01 \\
0.165\end{array}$ & $\begin{array}{r}1 \\
28 \\
\end{array}$ & $\begin{array}{c}2 \\
35 \cdot 5 \\
\end{array}$ & $\begin{array}{r}2 \\
15 \\
\end{array}$ & $\stackrel{1}{15 \cdot 5}$ \\
\hline Native Indian & 0.04 & 32 & $8 \cdot 5^{* *}$ & 18 & $4 * *$ \\
\hline $\begin{array}{l}\text { Jewish } \\
\text { Asian } \\
\text { Negro } \\
\text { Scandinavian } \\
\text { Other } \\
\text { Total }\end{array}$ & $\begin{array}{l}0.02 \\
0.007 \\
0.001 \\
0.035 \\
0.03\end{array}$ & $\begin{array}{r}2 \\
2 \\
1 \\
2 \\
3 \\
219\end{array}$ & $\begin{array}{l}4 \\
1 \\
0 \\
7 \cdot 5 \\
6 \cdot 5\end{array}$ & $\begin{array}{r}1 \\
0 \\
0 \\
2 \\
2 \\
95\end{array}$ & $\begin{array}{c}2 \\
0 \cdot 5 \\
0 \\
3 \\
3\end{array}$ \\
\hline
\end{tabular}

"Statistically significant difference. ${ }^{* *}$ Highly significant. 
of Manitoba is ethnically diverse, and the observed and expected numbers of clefts based on the proportion that each ethnic group represents in the total Manitoba population are shown in table 2. Tables based on maternal and paternal origin were so similar that they have been combined. There was a significant excess of Mennonite infants with CLP and a highly significant excess of both CLP and CP among Amerindian infants. These ethnic variations may represent a difference in the incidence of clefting or they may simply reflect differences in fertility. Unfortunately no ethnic specific fertility data are available for the general provincial population. However, it is difficult to attribute a specific increase in CLP among the Mennonites to a difference in fertility. Moreover, the magnitude of the excess is partially hidden, as the control group contains all persons of German and Dutch origin whereas the clefting population has been noted to be heavily weighted towards Mennonites (considered German or Dutch by Statistics Canada). The increased incidence among Amerindians is of such a magnitude as to suggest that increased fertility is not the sole explanation. Lowry and Renwick ${ }^{12}$ and Emmanuel et al $^{8}$ have reported an excess of facial clefting among Amerindians. This ethnic distribution was reflected in a significant excess of CLP in Eastern and Central Manitoba, where many Mennonite communities are located, and of $\mathrm{CP}$ in Northern Manitoba, where a larger proportion of the population is native.

Twenty-eight of $189(14.8 \%)$ CLP cases and 18 of $82(22.0 \% ; \mathrm{p}<0.05) \mathrm{CP}$ cases were illegitimate, compared to a $12 \cdot 8 \%$ rate for the general population in the middle year of the study. ${ }^{10}$ Fourteen of the 18 illegitimate births in the $\mathrm{CP}$ group were Amerindian and a higher frequency of both clefting and illegitimacy among the native group accounted for the excess of illegitimate births in the CP cases.

Although the numbers were small, there was a 3- and 4.5-fold excess of consanguinity (third cousins or closer) between the parents of the CLP and $\mathrm{CP}$ patients, respectively, over that of $0.8 \%$ recorded for a local population (Hamerton et al, unpublished data). Most of the relatively limited data available do not support an association of consanguinity with clefting, ${ }^{1}$ although a possible effect in cleft lip was noted by Woolf ${ }^{5}$ and in CP by Fujino et al..$^{13}$ Sixteen of $138(11.6 \%)$ CLP mothers and 12 of $63(19.0 \%)$ of CP mothers reported first trimester illnesses. The difference between the two groups is statistically significant $(p<0.05)$. Retrospective maternal memory bias would be expected to be greater among mothers of the more visible and emotionally overlaid CLP group and the frequency of first trimester illnesses reported is considerably greater than that reported by Fraser, ${ }^{1}$ who found no significant differences between normal controls and cleft palate mothers.

Previous stillbirths were significantly more frequent in CLP mothers (10 in $148 ; 6.8 \%$ ) than in the general population of Manitoba $(2 \cdot 7 \%)$ (Hamerton et al, unpublished data; $\mathrm{p}<0.01$ ), whereas the frequency in CP mothers ( 3 in $75 ; 4.0 \%)$ was not significantly different from the expected rate. A past history of spontaneous abortion occurred with the same frequency among CLP $(20.7 \%), C P$ $(20.3 \%)$, and women in the general population (17.1\%) (Hamerton et al, unpublished data). An unexpected finding was that $7 \cdot 6 \%$ of CLP mothers and $10 \%$ of $\mathrm{CP}$ mothers had given birth to an additional child with a different malformation.

Variables that did not appear to have any relationship to the occurrence of clefting included birthweight, gestational age, season of birth, twin births, maternal smoking during pregnancy, parental education, and occupation.

\section{Family data}

The patients in the MCA and syndrome groups represent a broad range of known and unknown aetiologies (included in appendix). As expected, a number of clefting syndromes are represented and some show a positive family history. On the other hand there are several syndromes (for example Down's, Goldenhar's, Marfanoid hypermobility) where cleft palate is a less frequent component of the syndrome, and it is perhaps significant that a positive family history of isolated clefting (that is, without the syndrome) is common in these patients. This supports the concept that even in syndromes of known aetiology, the expression of a particular malformation may be influenced by the genetic background of the individual patient.

The frequency of clefting among first and second degree relatives of CLP and CP cases is given in table 3. CLP occurred 33 times more frequently among first degree relatives (sibs), and 13 times more frequently among second degree relatives, than in the general population; the figures for CP were 119 and 21.5 times, respectively. This increased rate in relatives with a rapid fall-off in incidence with degree of relationship is compatible with polygenic inheritance, ${ }^{156}$ but we could not assess the rates in third degree relatives. The lower frequency of clefting in parents as compared to sibs of affected children is perhaps explained by a decreased genetic fitness among cleft patients. Similar data were reported by Woolf ${ }^{5}$ and Bear. ${ }^{6}$

Table 4 shows that the recurrence rate in sibs is influenced by the presence or absence of other 
TABLE 3 Clefts in first and second degree relatives of probands

\begin{tabular}{|c|c|c|c|c|}
\hline & \multicolumn{3}{|c|}{ First degree relatives } & \multirow{2}{*}{$\begin{array}{l}\begin{array}{l}\text { Second degree } \\
\text { relatives }\end{array} \\
\text { (Grandparents, } \\
\text { aunts, uncles, } \\
\text { nieces, nephews) }\end{array}$} \\
\hline & Sibs & Fathers & Mothers & \\
\hline \multicolumn{5}{|l|}{ CLP } \\
\hline Total No & 350 & 179 & 185 & 1187 \\
\hline $\begin{array}{l}\text { No affected } \\
\text { Frequency }\end{array}$ & 12 & 5 & 2 & 16 \\
\hline affected & $3.42 \%$ & $\begin{array}{c}2.8 \% \\
\text { Parents }=\end{array}$ & $2.0 \%$ & $1 \cdot 35 \%$ \\
\hline \multicolumn{5}{|c|}{$2010160-2070$} \\
\hline \multirow{3}{*}{$\begin{array}{l}\text { Total No } \\
\text { No affected } \\
\text { Frequency } \\
\text { affected }\end{array}$} & 146 & 69 & 83 & 504 \\
\hline & 8 & 1 & 3 & 5 \\
\hline & $5.48 \%$ & $\begin{array}{l}1.44 \% \\
\text { Parents }=\end{array}$ & $\begin{array}{r}3.6 \% \\
2.52 \%\end{array}$ & $0.99 \%$ \\
\hline
\end{tabular}

TABLE 4 Family history and sib recurrence rate

\begin{tabular}{lclll}
\hline Family history & \multicolumn{1}{c}{ CLP } & \multicolumn{3}{c}{$C P$} \\
\cline { 2 - 5 } & $\begin{array}{l}\text { Total } \\
\text { sibs }\end{array}$ & $\begin{array}{l}\text { Sibs } \\
\text { affected }\end{array}$ & $\begin{array}{l}\text { Total } \\
\text { sibs }\end{array}$ & $\begin{array}{l}\text { Sibs } \\
\text { affected }\end{array}$ \\
\hline None & 267 & 6 & 115 & 2 \\
Cleft in parent & 8 & 0 & 2 & $\begin{array}{l}(1.74 \%) \\
(50.0 \%)\end{array}$ \\
$\begin{array}{l}\text { Cleft in 2nd degree } \\
\text { relative }\end{array}$ & 25 & 3 & 16 & $\begin{array}{l}3 \\
(18.8 \%)\end{array}$ \\
$\begin{array}{l}\text { Cleft in 3rd degree } \\
\text { relative }\end{array}$ & 52 & $\begin{array}{l}(12.0 \%) \\
(5.76 \%)\end{array}$ & 37 & $\begin{array}{l}2 \\
(5.41 \%)\end{array}$ \\
\hline
\end{tabular}

affected family members. Sibs from CLP and CP families where the index case is the sole affected member are at significantly lower risk than sibs from families where a second or third degree relative is affected. Thus, the genetic component of both CLP and CP appears to be high and the heritability, based on sib data, was calculated to be $75 \%$ and
$77 \%$, respectively. ${ }^{14}$ There was the same increasec number of Mennonites among the familial CLP and: of Amerindians among the familial CLP and $\mathrm{CP}_{\mathrm{C}}^{\mathrm{F}}$ groups as was seen in the total groups. Parental age data and sex ratio showed no significant difference between familial and sporadic cases for either CLP ore CP.

There were few sibs born to families where a parent was also affected and this was apparentlyes because of restriction of further reproduction once $a \vec{\circ}$ child with a cleft was born. The mean sibship size for CLP and CP families in this study was 3.4 and $3 \cdot 6$, respectively, but in CLP and CP families where a parent was also affected the mean number of sibs waso $1 \cdot 8$ and $0 \cdot 7$, respectively.

Woolf et $a^{15}$ suggested that most polygenic casesi of CLP lack associated malformations and that cases $\vec{N}$ of CLP with associated malformation either result $V$ from rare mutant genes, or from some teratological 은 agent, or from chromosomal aberrations. In a study of CLP in $1971^{5}$ he found that the sib recurrence risk in cases where the index case had an associated $=$ malformation was significantly lower than in cases $\overrightarrow{0}$ where there were no additional defects. $B e a{ }^{6}{ }^{\text {found }}{ }^{\infty}$ no variation dependent upon associated malformations. Although the numbers are small our frequencyo of affected relatives in the CLP and CP groups was consistently greater when the proband had an associated major or minor malformation or both $\frac{\mathrm{D}}{\mathrm{O}}$ (table 5). The affected relatives lacked the associated 0 malformation. The excess of minor anomalies in $\overrightarrow{\overrightarrow{0}}$ the familial group could be considered equivalent to the fluctuating dermatoglyphic asymmetry noted in sibs and parents of CLP cases by Woolf and Gianas. ${ }^{16}$ The authors considered this as evidence of polygenic inheritance of CLP.

Thus, recurrence rates among sibs of index cases $\frac{5}{3}$

TABLE 5 Frequency of affected relatives as a function of additional major or minor malformation in proband

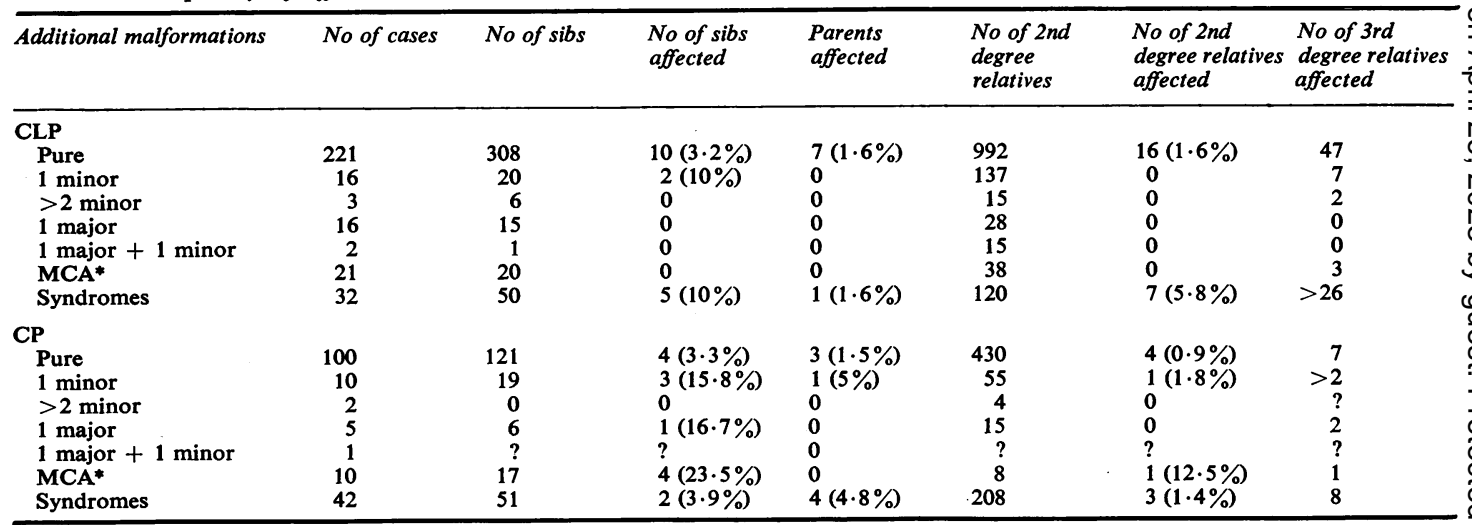

*MCA, multiple congenital anomalies (includes 'private' syndromes). 
TABLE 6 Sib recurrence rates as function of presence of cleft in relatives and malformations in proband

\begin{tabular}{|c|c|c|c|c|c|c|c|}
\hline $\begin{array}{l}\text { Affected } \\
\text { relative }\end{array}$ & Proband & $\begin{array}{l}C P \\
\text { Total sibs }\end{array}$ & No of affected & Frequency & $\begin{array}{l}C L P \\
\text { Total sibs }\end{array}$ & No of affected & Frequency \\
\hline None & $\begin{array}{l}\text { No malformation } \\
\geqslant 1 \text { minor } \\
1 \text { major } \pm \text { minor }\end{array}$ & $\begin{array}{r}97 \\
12 \\
2\end{array}$ & $\begin{array}{l}1 \\
1 \\
0\end{array}$ & $\begin{array}{l}1 \% \\
8 \% \\
-\end{array}$ & $\begin{array}{r}231 \\
22 \\
4\end{array}$ & $\begin{array}{l}4 \\
1 \\
0\end{array}$ & $\begin{array}{l}1 \cdot 7 \% \\
4.6 \% \\
0 \%\end{array}$ \\
\hline Parent & $\begin{array}{l}\text { No malformation } \\
\geqslant 1 \text { minor } \\
1 \text { major } \pm \text { minor }\end{array}$ & $\begin{array}{l}0 \\
2 \\
0\end{array}$ & $\begin{array}{l}0 \\
1 \\
0\end{array}$ & $\overline{50} \%$ & $\begin{array}{l}8 \\
0 \\
0\end{array}$ & $\begin{array}{l}\mathbf{0} \\
\mathbf{0} \\
\mathbf{0}\end{array}$ & $\frac{0 \%}{-}$ \\
\hline 2nd degree & $\begin{array}{l}\text { No malformation } \\
\geqslant 1 \text { minor } \\
1 \text { major } \pm \text { minor }\end{array}$ & $\begin{array}{r}15 \\
0 \\
0\end{array}$ & $\begin{array}{l}2 \\
0 \\
0\end{array}$ & $\begin{array}{l}13 \cdot 3 \% \\
-\end{array}$ & $\begin{array}{r}25 \\
0 \\
0\end{array}$ & $\begin{array}{l}3 \\
0 \\
0\end{array}$ & $\begin{array}{l}12 \% \\
-\end{array}$ \\
\hline$\geqslant 3$ rd degree & $\begin{array}{l}\text { No malformation } \\
\geqslant 1 \text { minor } \\
1 \text { major } \pm \text { minor }\end{array}$ & $\begin{array}{r}27 \\
11 \\
0\end{array}$ & $\begin{array}{l}1 \\
1 \\
0\end{array}$ & $\begin{array}{l}3.7 \% \\
9.1 \% \\
\end{array}$ & $\begin{array}{r}47 \\
5 \\
0\end{array}$ & $\begin{array}{l}2 \\
1 \\
0\end{array}$ & $\begin{array}{c}4.3 \% \\
20 \% \\
-\end{array}$ \\
\hline
\end{tabular}

are influenced by both the presence of clefts in relatives and of malformations in the proband. In table 6 the sib recurrence rates are presented as a function of both these variables. The numbers are too small to draw any conclusions, but presented in this way the data could be combined with additional series. However, there is a suggestion that higher sib recurrence rates are associated with the presence of minor anomalies when either no relative or a third degree relative is affected, and with no minor anomalies when a second degree relative is affected. If this trend were to continue with larger numbers it might provide clues as to the aetiological heterogeneity in cases of CLP and CP. Our numbers were not large enough to reflect meaningfully on the possible effects of the severity of the defect or the sex of the proband on recurrence rates. However, the data in the Appendix are in a form that could be combined with additional studies. In addition, pedigrees of the familial cases are available from the authors on request.

In conclusion, this study has provided incidence rates for the different forms of facial clefting in Manitoba and has confirmed an ethnic variation in incidence. The recurrence rates among sibs have been shown to be strongly influenced by the presence of affected relatives other than the proband and of malformations in the proband. There is a suggestion that these latter two variables may not be independent. It is clear that facial clefts have diverse aetiologies and that only by precise analysis of cases subdivided according to their physical and family history and demographic data will it be possible to obtain meaningful insights into the aetiologies and genetics of CLP and CP. Unfortunately, as one continues to subdivide into categories, the requirements for greater numbers of cases and for accuracy of recording increase and it becomes increasingly difficult for one centre to obtain adequate data. Our study suffers the defects of a retrospective study, including loss of cases and incomplete data. This is particularly true with respect to family history information and the recording of minor anomalies. For this reason we believe that a long-term, prospective, multicentre study with standard recording of family history, assessment of minor and major malformations, face shape, and follow-up may be required to provide answers to the questions that remain regarding the genetics and counselling of CLP and CP.

We are grateful to the many patients and their physicians who co-operated in this study; to Dr J L Hamerton who allowed us to use population data collected in his newborn chromosome survey; to Drs J A Evans, P W Hsu, and F C Fraser for encouragement and guidance; and to Mr Ken Carpenter and Ms Barb Ruchkall of the University of Manitoba Computer Department for assistance in analysing the data. This work was submitted as partial fulfilment of a B.Sc in Medicine at the University of Manitoba and was funded by the Children's Hospital of Winnipeg Research Foundation. Mrs Lilian Gordon patiently typed the numerous revisions of the manuscript and the appendix.

\section{References}

1 Fraser FC, The genetics of cleft lip and cleft palate. Am J Hum Genet 1970;22:336-52.

2 Drillien CM, Ingram TTS, Wilkinson EM. The causes and natural history of cleft lip and palate. Edinburgh: Livingstone, 1966.

3 Hay S. Incidence of selected congenital malformations in Iowa. Am J Epidemiol 1971;94:572-85.

4 Greene JC. Epidemiology of congenital clefts of the lip and palate. Public Health Rep 1963;78:589-602.

5 Woolf CM. Congenital cleft lip. J Med Genet 1971;8: 65-83.

6 Bear JC. A genetic study of facial clefting in northern England. Clin Genet 1976;9:277-84.

7 Chi SCC. Cleft lip and cleft palate in New South Wales. Aust Dent J 1974;19:111-7. 
8 Emmanuel I, Culver BH, Erickson JD, Guthrie B, Schuldberg $\mathrm{D}$. The further epidemiological differentiation of cleft lip and palate: a population study of clefts in King County, Washington, 1956-1965. Teratology 1973;7: 271-82.

- Mitchell SC, Korones SB, Berendes HW. Incidence of congenital heart disease in 56,109 births. Circulation $1971 ; 43: 323-32$.

10 Statistics Canada. Vital statistics. Dominion Bureau of Statistics Annual Report, Canada, 1970.

11 Burdi AR. Epidemiology, etiology and pathogenesis of cleft lip and palate. Cleft Palate $J$ 1977;14:262-8.

12 Lowry RB, Renwick DHG. Incidence of cleft lip and palate in British Columbia Indians. J Med Genet 1969;6: 67-9.

13 Fujino H, Tanaka K, Sanui Y. Genetic study of cleft lips and cleft palates based upon 2828 Japanese cases $\overparen{D}$ Kyushi J Med Sci 1963;14:317-31.

14 Falconer DS. The inheritance of liability to certain diseases, estimated from the incidence among relatives? Ann Hum Genet 1965;29:51-71.

15 Woolf CM, Woolf RM, Broadbent TR. Cleft lip anco palate in parent and child. Plast Reconstr Surg 1969;44 $\overline{\bar{s}}$ 436-40.

16 Woolf CM, Gianas AD. A study of fluctuating dermato $\mathbb{D}$ glyphic asymmetry in the sibs and parents of cleft lipu propositi. Am J Hum Genet 1977;29:503-7.

Requests for reprints to Dr Joan Welch, $495 \mathrm{St}_{-}$ Anthony Avenue, Winnipeg, Manitoba R2V 0S4, Canada. 